\title{
Association between asymptomatic hyperuricemia and new-onset chronic kidney disease in Japanese male workers: a long-term retrospective cohort study
}

\author{
Masatoshi Kawashima ${ }^{1 \dagger}$, Koji Wada $^{2^{*}+}$, Hiroshi Ohta ${ }^{2}$, Hiroyuki Terawaki ${ }^{3}$ and Yoshiharu Aizawa ${ }^{2}$
}

\begin{abstract}
Background: Hyperuricemia is prevalent in patients with chronic kidney disease (CKD). We explored the hypothesis that asymptmatic hyperuricemia may be associated with new-onset CKD.

Methods: The participants were all male factory workers in Kanagawa, Japan ( $n=1,285)$. All were over 40 years of age and had undergone annual health examinations from 1990 to 2007. Individuals with a history of gouty attacks were excluded from the study. A retrospective cohort study was conducted by following the estimated glomerular filtration rate (eGFR) for each participant over a maximum period of 18 years. The endpoint was new-onset CKD defined as eGFR $<60 \mathrm{~mL} / \mathrm{min} / 1.73 \mathrm{~m}^{2}$. The associations between new-onset CKD and the presence of hyperuricemia, low serum high-density lipoprotein cholesterol, hypertension, diabetes, and obesity were analyzed.

Results: The mean ( \pm standard deviation) follow-up period was 95.2 ( \pm 66.7 ) months, and new-onset CKD was observed in 100 participants (7.8\%) during this follow-up. Cox proportional hazards model revealed that the hazard ratio of new-onset CKD due to hyperuricemia, low serum high-density lipoprotein cholesterol, hypertension and obesity were 3.99 (95\% confidence interval: 2.59-6.15), 1.69 (1.00-2.86), 2.00 (1.29-3.11) and 1.35 (0.87-2.10), respectively. Concerning hyperuricemia, low serum high-density lipoprotein cholesterol, hypertension and obesity, the log-rank tests showed $P$ values of $<0.01,0.01,<0.01$ and $<0.01$, respectively.

Conclusion: The results of this study suggest that asymptomatic hyperuricemia is a predictive factor for new-onset CKD for Japanese male workers.
\end{abstract}

Keywords: chronic kidney disease, hyperuricemia, glomerular filtration rate, cohort, Japan

\section{Background}

End-stage renal disease (ESRD) poses a serious public health problem as a result of the costs of treatments such as dialysis and transplantation and harms the quality of life. Chronic kidney disease (CKD) precedes ESRD, and the progression of CKD to ESRD can be preventable by appropriate treatment. Prevention of newonset CKD could effectively target ESRD. In 2002, the Kidney Disease Outcomes Quality Initiative of the

\footnotetext{
* Correspondence: kwada-sgy@umin.ac.jp

+ Contributed equally

${ }^{2}$ Department of Preventive Medicine and Public Health, Kitasato University

School of Medicine, Sagamihara, Japan

Full list of author information is available at the end of the article
}

National Kidney Foundation gave a definition and classification system for CKD, and CKD is defined as either glomerular filtration rate (GFR) $<60 \mathrm{~mL} / \mathrm{min} / 1.73 \mathrm{~m}^{2}$ or kidney damage lasting for at least 3 months [1]. The estimated prevalences of CKD measured as GFR $<60$ $\mathrm{mL} / \mathrm{min} / 1.73 \mathrm{~m}^{2}$ are $8.1 \%$ in the United States [2] and $10.6 \%$ in Japan [3].

Previous studies have established hypertension [4-9] and diabetes [10-13] as predictive factors for CKD. Dyslipidemia $[6,14,15]$, obesity $[7,16]$ and hyperuricemia [17-20] have also been suggested to be predictive factors for CKD. However, it is not clear if asymptomatic hyperuricemia without gouty attacks is a risk factor for CKD. The aim of this study was to determine the 
associations between new-onset CKD and asymptomatic hyperuricemia, low serum high-density lipoprotein cholesterol (HDL-C), hypertension, diabetes and obesity in male factory workers over 40 years of age in Kanagawa, Japan.

\section{Methods Study Population}

The participants were all male factory workers over 40 years of age who had undergone annual medical examinations from 1990 to 2007. This retrospective cohort study covered a maximum period of 18 years. To investigate the effects of asymptomatic hyperuricemia, 41 participants with a history of gouty attacks were excluded from the analysis. Participants with only one year of data, those lacking follow-up data, or those with incomplete data were also excluded.

\section{Disease Criteria}

The presence of hyperuricemia, low serum HDL-C, hypertension, diabetes, and obesity were based on data from the participants' first-year medical examinations. Hyperuricemia was defined as a uric acid level of $>7.0$ $\mathrm{mg} / \mathrm{dL}$. Low serum HDL-C was defined as HDL-C $<40$ $\mathrm{mg} / \mathrm{dL}$. Hypertension was defined as a systolic blood pressure of $\geq 140 \mathrm{mmHg}$ or diastolic blood pressure of $\geq 90 \mathrm{mmHg}$. Diabetes was defined as a fasting blood sugar level of $\geq 126 \mathrm{mg} / \mathrm{dL}$. Obesity was defined as a body mass index (BMI) of $\geq 25 \mathrm{~kg} / \mathrm{m}^{2}$.

\section{Outcomes}

The endpoint was new-onset CKD. New-onset CKD was defined as the time point when estimated glomerular filtration rate (eGFR) fell below $60 \mathrm{~mL} / \mathrm{min} / 1.73 \mathrm{~m}^{2}$. The eGFR was calculated based on the participant's age and serum creatinine $(\mathrm{Cr})$ level, using the equation:

$$
\mathrm{eGFR}=194 \times \mathrm{Cr}^{-1.094} \times \mathrm{Age}^{-0.287}
$$

determined by the Japanese Society of Nephrology [21]. In this study, serum $\mathrm{Cr}$ was measured using the Jaffe method from 1990 to 2002, and using the enzyme method from 2003 to 2007. Because the equation for estimating GFR used in this study is based on an enzyme method, eGFR for the period from 1990 to 2002 was calculated using the serum $\mathrm{Cr}$ level after subtraction of $0.2 \mathrm{mg} / \mathrm{dL}$ from the original serum Cr level [22]. Participants were excluded from the analysis if their earliest year's eGFR was $<60 \mathrm{~mL} / \mathrm{min} / 1.73 \mathrm{~m}^{2}$, if they had only 1 year's worth of data or if they lacked follow-up data.

\section{Statistical Analysis}

The associations between new-onset CKD and the presence of hyperuricemia, low serum HDL-C, hypertension, diabetes, and obesity were analyzed. The covariates included age, hyperuricemia, low serum HDL-C, hypertension, diabetes and obesity. The follow-up period (in months) was the survival variable and new-onset CKD was a state variable. To adjust for age and the presence of disease as confounders, multivariate analysis was performed using Cox regression analysis [23]. A hazard ratio and $95 \%$ confidential interval (CI) were derived for each covariate. The hazard ratio was determined to be significant when the $P$ value was $<0.05$. In addition, KaplanMeier curves and log-rank tests were used to estimate the cumulative incidence of the covariates showing a significant hazard ratio [24]. The Japanese version of SPSS 17.0 for Windows was used for the analyses [25].

\section{Ethical Approval}

This study was conducted with the approval of the ethics committee of Kitasato University School of Medicine.

\section{Results}

The study involved 1,285 participants with a mean ( \pm standard deviation [SD]) follow-up period of $95.2( \pm$ 66.7) months. Of these participants, 100 (7.8\%) developed CKD during the follow-up period, and their mean $( \pm \mathrm{SD})$ follow-up period was $89.3( \pm 62.0)$ months. The mean $( \pm$ SD) follow-up period for participants who did not develop CKD was 95.7 ( \pm 67.1) months. Table 1 shows the baseline characteristics of the participants in terms of age, levels of uric acid, HDL-C, systolic blood pressure, diastolic blood pressure, fasting blood sugar, and BMI. Hyperuricemia was detected in 166 participants (12.9\%), low serum HDL-C in 153 (11.9\%), hypertension in 255 (19.8\%), diabetes in 51 (4.0\%), and obesity in 255 (19.8\%).

Table 2 shows the prediction for new-onset CKD during followed-up period. Of the participants with hyperuricemia at baseline, 32 (19.3\%) developed CKD during the follow-up period. The results of Cox regression analysis revealed that the hazard ratio for new-onset CKD in the participants with hyperuricemia was 3.99 (95\% CI: 2.59-6.15), showing a significant association between hyperuricemia and new-onset CKD. Likewise, the hazard ratio for new-onset CKD was 1.69 (95\% CI: 1.00-2.86) in the participants with low serum HDL-C and 2.00 (95\% CI: 1.29-3.11) in those with hypertension, indicating significant associations between new-onset CKD and these variables. However, a hazard ratio of 0.56 (95\% CI: 0.171.77) indicated no significant association between newonset CKD and diabetes. The hazard ratio was 1.35 (95\% CI: 0.87-2.10) in the participants with obesity, indicating a weak association.

The cumulative incidence of CKD was analyzed by the Kaplan-Meier method using the three variables (hyperuricemia, low serum HDL-C, and hypertension) showing 
Table 1 Baseline characteristics of participants

\begin{tabular}{lcc}
\hline & $\begin{array}{c}\text { Participants } \\
\text { (n = 1,285) }\end{array}$ & $\%$ \\
\hline Age (yrs) & & \\
$\quad 40$ & 433 & 33.7 \\
$41-45$ & 273 & 21.2 \\
$46-50$ & 276 & 21.5 \\
$51-55$ & 220 & 17.1 \\
$\quad \geq 56$ & 83 & 6.5 \\
Uric acid (mg/dL) & & \\
$\quad>7.0$ & 166 & 12.9 \\
$\quad \leq 7.0$ & 1,119 & 87.1 \\
HDL-C (mg/dL) & 153 & \\
$\quad<40$ & 1,132 & 88.1 \\
$\quad \geq 40$ & & \\
Blood pressure (mmHg) & 255 & 19.8 \\
$\quad$ SBP $\geq 140$ or DBP $\geq 90$ & 1,030 & 80.2 \\
SBP $<140$ and DBP $<90$ & & \\
Fasting blood sugar (mg/dL) & 51.9 \\
$\quad \geq 126$ & 1,234 & 96.0 \\
$<126$ & & \\
Body mass index (kg/m ${ }^{2}$ ) & 255 & 19.8 \\
$\quad \geq 25.0$ & 1,030 & 80.2 \\
$<25.0$ & & \\
\hline
\end{tabular}

HDL-C, high-density lipoprotein cholesterol

SBP, systolic blood pressure; DBP, diastolic blood pressure.

significant associations and the one variable (obesity) showing a weak association with new-onset CKD in the Cox proportional hazards model (Figure 1). Concerning hyperuricemia, low serum HDL-C, hypertension and obesity, the log-rank tests showed $P$ values of $<0.01$
(Figure 1-A), 0.01 (Figure 1-B), < 0.01 (Figure 1-C) and $<0.01$ (Figure 1-D), respectively.

\section{Discussion}

We investigated the associations between new-onset CKD and asymptomatic hyperuricemia without gouty attacks, low serum HDL-C, hypertension, diabetes and obesity in Japanese male factory workers over 40 years of age. The results showed a significantly higher incidence of new-onset CKD in participants with asymptomatic hyperuricemia. A significantly higher incidence of new-onset CKD was also found in participants with low serum HDL-C and hypertension. The incidence of newonset CKD tended to be higher, but not significantly, in obese participants, whereas no significant increase in the incidence of new-onset CKD was found in those with diabetes.

Several studies have reported possible associations between gouty attacks and renal function $[26,27]$ and have suggested an association between hyperuricemia and CKD [17-20]. However, previous studies were not noticed about asymptomatic hyperuricemia without gouty attacks. Hyperuricemia in this study was defined as a uric acid level above $7.0 \mathrm{mg} / \mathrm{dL}$ without gouty attacks, and the hazard ratio for new-onset CKD in participants with hyperuricemia was 3.99 , indicating a significant association. In addition, significant negative correlations were found between the uric acid values at the start of follow-up and the GFR values at the start of follow-up, after follow-up for 5 years, and after followup for 10 years (correlation coefficient: at the start of follow-up, $-0.21 \mathrm{p}<0.001$; after 5 years, $-0.20 \mathrm{p}<0.001$;

Table 2 Associations between predictors and new-onset CKD during a maximum period of 18 years follow-up

\begin{tabular}{|c|c|c|c|c|c|}
\hline Predictors & $\begin{array}{l}\text { Duration } \pm \text { SD } \\
\text { (months) }\end{array}$ & Cases & $\begin{array}{c}\text { Incidence } \\
(\%)\end{array}$ & Hazard ratio & $95 \% \mathrm{Cl}$ \\
\hline \multicolumn{6}{|l|}{ Uric acid (mg/dL) } \\
\hline$>7.0$ & $76.3 \pm 63.3$ & 32 & 19.3 & 3.99 & $2.59,6.15$ \\
\hline$\leq 7.0$ & $98.0 \pm 66.8$ & 68 & 6.1 & 1.00 & \\
\hline \multicolumn{6}{|l|}{$\mathrm{HDL}-\mathrm{C}(\mathrm{mg} / \mathrm{dL})$} \\
\hline$<40$ & $89.3 \pm 61.5$ & 18 & 11.8 & 1.69 & $1.00,2.86$ \\
\hline$\geq 40$ & $96.0 \pm 67.4$ & 82 & 7.2 & 1.00 & \\
\hline \multicolumn{6}{|l|}{ Blood pressure (mmHg) } \\
\hline $\mathrm{SBP} \geq 140$ or $\mathrm{DBP} \geq 90$ & $83.5 \pm 62.8$ & 33 & 12.9 & 2.00 & $1.29,3.11$ \\
\hline $\mathrm{SBP}<140$ and $\mathrm{DBP}<90$ & $98.1 \pm 67.4$ & 67 & 6.5 & 1.00 & \\
\hline \multicolumn{6}{|l|}{ Fasting blood sugar (mg/dL) } \\
\hline$\geq 126$ & $95.1 \pm 66.0$ & 3 & 5.9 & 0.56 & $0.17,1.77$ \\
\hline$<126$ & $95.2 \pm 66.8$ & 97 & 7.9 & 1.00 & \\
\hline \multicolumn{6}{|l|}{ Body mass index $\left(\mathrm{kg} / \mathrm{m}^{2}\right)$} \\
\hline$\geq 25.0$ & $93.2 \pm 66.4$ & 34 & 12.5 & 1.35 & $0.87,2.10$ \\
\hline$<25.0$ & $95.7 \pm 66.8$ & 66 & 6.5 & 1.00 & \\
\hline
\end{tabular}

CKD, chronic kidney disease; SD, standard deviation; $\mathrm{Cl}$, confidence interval.

HDL-C, high-density lipoprotein cholesterol; SBP, systolic blood pressure; DBP, diastolic blood pressure. 


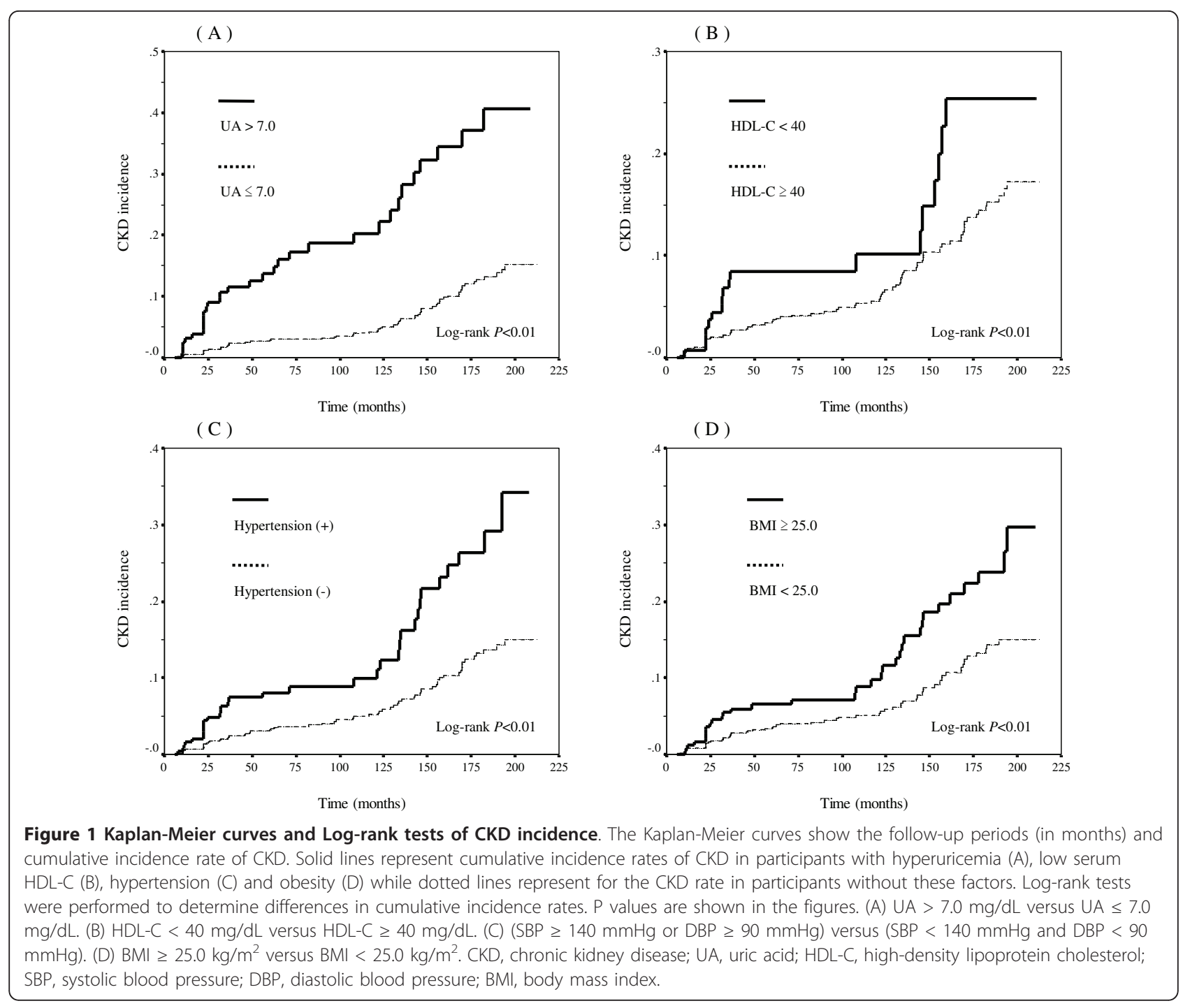

and after 10 years:-0.22 p < 0.001) (data not shown). A uric acid level of $7.0 \mathrm{mg} / \mathrm{dL}$ is the diagnostic standard for hyperuricemia in Japan [28]. Obermayr et al stated in their report on 21,475 participants followed for 7 years, that the risk of new-onset CKD was increased by a factor of 1.74 in those whose uric acid levels were 7.0$8.9 \mathrm{mg} / \mathrm{dL}$, and by a factor of 3.12 in those whose uric acid levels were $\geq 9.0 \mathrm{mg} / \mathrm{dL}$ [17]. Iseki et al. conducted a study in Japan and reported that the hazard ratio for progression to ESRD was 5.77 in women with uric acid levels of $\geq 6.0 \mathrm{mg} / \mathrm{dL}$, showing a significant association, whereas there was no significant association between progression to ESRD and uric acid levels in men with uric acid levels of $\geq 7.0 \mathrm{mg} / \mathrm{dL}$ [19]. A follow-up study of patients with immunoglobulin A nephropathy for at least 8 years reported that serum creatinine $(\mathrm{Cr})$ levels were significantly elevated in patients with hyperuricemia [20]. Hyperuricemia appeared to be affected by other lifestyle-related diseases such as hypertension, diabetes and dyslipidemia, but a significant association between hyperuricemia and new-onset CKD remained even after adjusting for factors related to hypertension, low serum HDL-C, obesity and diabetes. In this study, the hazard ratio for asymptomatic hyperuricemia was greater than those for other factors, including hypertension. Asymptomatic hyperuricemia was therefore suggested not only to be a predictive factor for CKD, but also to be a stronger predictor than established factors such as hypertension and diabetes.

Dyslipidemia is thought to be a risk factor for newonset CKD. Previous studies detected associations between CKD and decreased HDL-C [6,7,14,15,29], increased total cholesterol $[29,30]$, increased low-density lipoprotein cholesterol $[14,28,30]$, and increased triglycerides $[6,15]$. However, several other studies found no such significant associations, and further investigation 
may be needed to clarify the association between dyslipidemia and CKD. Low serum HDL-C in this study was classified as HDL-C levels $<40 \mathrm{mg} / \mathrm{dL}$, which is the diagnostic standard for low HDL-C in the United States (NCEP ATP III)[31] and in Japan (Japan Atherosclerosis Society; Guidelines for Prevention of Atherosclerotic Cardiovascular Diseases)[32]. When serum HDL-C was low, the incidence of new-onset CKD increased significantly (hazard ratio: 1.69), supporting an association between dyslipidemia and CKD.

An association between hypertension and renal disease has been established in a number of previous studies [4-9]. Increases in blood pressure have also been reported to be associated with increases in the incidence of ESRD $[8,33,34]$, and progression of CKD can be prevented by antihypertensive treatment $[5,8,9]$. In this study, hypertension was defined as a systolic blood pressure of $\geq 140$ $\mathrm{mmHg}$ or diastolic blood pressure of $\geq 90 \mathrm{mmHg}$. This is the standard classification for stage I hypertension in the United States (JNC7)[35] and mild hypertension in Japan (JSH2009)[36] and is used as the diagnostic standard for hypertension. The hazard ratio for new-onset CKD in our study was 2.00 , showing a significant association with hypertension. These results are consistent with those from several previous studies that also found an association between hypertension and CKD.

Diabetes is an established predictor of renal disease [10-13]. However, we found no significant association between diabetes and new-onset CKD. GFR decreases with the duration of diabetes, but it has been suggested that glomerular hyperfiltration occurs during the early stage of diabetes, leading to a temporary increase in GFR [37]. The mean ( \pm SD) follow-up period was 95.1 $( \pm 66.0)$ months in our participants with diabetes, but it is possible that the GFR was increased or not markedly decreased in some participants who were still in the hyperfiltration phase. Thus, it is necessary to determine the presence of new-onset CKD employing urinary albumin measurement in participants with diabetic nephropathy during the early stage. Diabetes reportedly did not significantly affect the progression of CKD in Japanese participants; significant reductions in GFR might not have been observed because of hyperfiltration, as observed in this study [6].

Obesity has been suggested to be a risk factor for ESRD $[7,16]$. Kramer et al. reported that the risk of new-onset CKD was increased by a factor of 1.21 in participants whose BMI was $25.0-29.9 \mathrm{~kg} / \mathrm{m}^{2}$ and by a factor of 1.40 in those whose BMI was $\geq 30 \mathrm{~kg} / \mathrm{m}^{2}$ [38]. However, a study conducted in Japanese participants found that a BMI of $\geq 25 \mathrm{~kg} / \mathrm{m}^{2}$ in male participants had no effect on the progression of CKD to stage III or more severe disease [6]. In our study, a BMI of $25 \mathrm{~kg} /$ $\mathrm{m}^{2}$ was used as the standard for defining obesity, according to the criteria for obesity in Japan (Guidelines for the Treatment of Obesity, 2006)[39]. The hazard ratio for new-onset CKD in participants with obesity was 1.35 , showing no significant association; however, a weak association was observed, since the $95 \%$ CI was 0.87-2.10. Further studies with longer follow-up periods in more participants are needed to clarify the association between obesity and new-onset CKD.

In this study, new-onset CKD was defined as GFR $<60$ $\mathrm{mL} / \mathrm{min} / 1.73 \mathrm{~m}^{2}$. It is therefore important to clarify the methods used for estimating the GFR; GFR-estimating equations for Japanese devised by the Japanese Society of Nephrology in March, 2008 [21]. Imai et al. previously reported a different equation for estimating GFR in Japanese participants [40], but it has been suggested that this might underestimate GFR values. The equation used in the current study was a revised version of the previous equation, and might produce more accurate estimates of GFR in the Japanese population. According to the diagnostic criteria for CKD, abnormal urinalysis results, such as proteinuria, and abnormal findings on echography, can also be used to diagnose CKD. However, in line with many previous studies, the current study defined CKD as GFR $<60 \mathrm{~mL} / \mathrm{min} / 1.73 \mathrm{~m}^{2}$.

Hyperuricemia, low serum HDL-C, hypertension, diabetes, and obesity were defined in this study based on the first year's data for each participant. Treatment for any of these diseases was not taken into account, except for the exclusion of any individuals with a history of gouty attacks. It is therefore possible that some of the participants who were classified as a uric acid level of $\leq$ $7.0 \mathrm{mg} / \mathrm{dL}$ were actually receiving treatment. In this case, compared with strictly extracting participants who have treatment of hyperuricemia, the power of statistically significance of the association between hyperuricemia and CKD could be low. However, hyperuricemia could be a predictive factor for new-onset CKD in this study, as suggested by the significant association between hyperuricemia and new-onset CKD. Conclusions

The results of this study suggest that asymptomatic hyperuricemia without gouty attacks is a predictive factor for new-onset CKD. Therefore, the appropriate treatment might reduce the number of patients of CKD.

\section{Abbreviations}

ESRD: end-stage renal disease; CKD: chronic kidney disease; GFR: glomerular filtration rate; HDL-C: high-density lipoprotein cholesterol; BMI: body mass index; eGFR: estimated glomerular filtration rate; $\mathrm{Cr}$ : creatinine; $\mathrm{Cl}$ : confidence interval; SD: standard deviation.

\section{Acknowledgements}

We would like to express our gratitude to staff members of the clinic at Mitsubishi Heavy Industries, General Machinery and Special Vehicle Headquarters for help in collecting the participants' data during annual health examinations. 


\section{Author details}

'Department of Occupational Health, Graduate School of Medical Sciences, Kitasato University School of Medicine, Sagamihara, Japan. ${ }^{2}$ Department of Preventive Medicine and Public Health, Kitasato University School of Medicine, Sagamihara, Japan. ${ }^{3}$ Division of Kidney and Hypertension, The Jikei University School of Medicine Kashiwa Hospital, Kashiwa, Japan.

\section{Authors' contributions}

MK and KW designed the study, and completed the manuscript. HO, HT and YA undertook statistical analyses and assisted with drafting the manuscript from a clinical perspective. All authors read and approved the final manuscript.

\section{Competing interests}

The authors declare that they have no competing interests.

Received: 8 October 2010 Accepted: 2 July 2011 Published: 2 July 2011

\section{References}

1. K/DOQI clinical practice guidelines for chronic kidney disease: evaluation, classification, and stratification. Am J Kidney Dis 2002, 39(2 Suppl 1):S1-266.

2. Coresh J, Selvin E, Stevens LA, Manzi J, Kusek JW, Eggers P, Van Lente F, Levey AS: Prevalence of chronic kidney disease in the United States. JAMA 2007, 298(17):2038-2047.

3. Imai E, Horio M, Watanabe T, Iseki K, Yamagata K, Hara S, Ura N, Kiyohara Y, Moriyama T, Ando Y, Fujimoto S, Konta T, Yokoyama H, Makino H, Hishida A, Matsuo S: Prevalence of chronic kidney disease in the Japanese general population. Clin Exp Nephrol 2009, 13(6):621-630.

4. Walker WG, Neaton JD, Cutler JA, Neuwirth R, Cohen JD: Renal function change in hypertensive members of the Multiple Risk Factor Intervention Trial. Racial and treatment effects. The MRFIT Research Group. JAMA 1992, 268(21):3085-3091.

5. Bakris GL, Williams M, Dworkin L, Elliott WJ, Epstein M, Toto R, Tuttle K, Douglas J, Hsueh W, Sowers J: Preserving renal function in adults with hypertension and diabetes: a consensus approach. National Kidney Foundation Hypertension and Diabetes Executive Committees Working Group. Am J Kidney Dis 2000, 36(3):646-661.

6. Yamagata K, Ishida K, Sairenchi T, Takahashi H, Ohba S, Shiigai T, Narita M, Koyama A: Risk factors for chronic kidney disease in a community-based population: a 10-year follow-up study. Kidney Int 2007, 71(2):159-166.

7. Fox CS, Larson MG, Leip EP, Culleton B, Wilson PW, Levy D: Predictors of new-onset kidney disease in a community-based population. JAMA 2004, 291(7):844-850.

8. Tozawa M, Iseki K, Iseki C, Kinjo K, Ikemiya Y, Takishita S: Blood pressure predicts risk of developing end-stage renal disease in men and women. Hypertension 2003, 41(6):1341-1345.

9. Vupputuri S, Batuman V, Muntner P, Bazzano LA, Lefante JJ, Whelton PK, He J: Effect of blood pressure on early decline in kidney function among hypertensive men. Hypertension 2003, 42(6):1144-1149.

10. Adler Al, Stevens RJ, Manley SE, Bilous RW, Cull CA, Holman RR: Development and progression of nephropathy in type 2 diabetes: the United Kingdom Prospective Diabetes Study (UKPDS 64). Kidney Int 2003, 63(1):225-232.

11. Araki S, Haneda M, Sugimoto T, Isono M, Isshiki K, Kashiwagi A, Koya D: Factors associated with frequent remission of microalbuminuria in patients with type 2 diabetes. Diabetes 2005, 54(10):2983-2987.

12. Ruggenenti P, Fassi A, llieva AP, Bruno S, lliev IP, Brusegan V, Rubis N, Gherardi G, Arnoldi F, Ganeva M, Ene-lordache B, Gaspari F, Perna A, Bossi A, Trevisan R, Dodesini AR, Remuzzi G: Preventing microalbuminuria in type 2 diabetes. N Engl J Med 2004, 351(19):1941-1951.

13. Andersen S, Brochner-Mortensen J, Parving HH: Kidney function during and after withdrawal of long-term irbesartan treatment in patients with type 2 diabetes and microalbuminuria. Diabetes Care 2003, 26(12):3296-3302.

14. Schaeffner ES, Kurth T, Curhan GC, Glynn RJ, Rexrode KM, Baigent C, Buring JE, Gaziano JM: Cholesterol and the risk of renal dysfunction in apparently healthy men. J Am Soc Nephrol 2003, 14(8):2084-2091.

15. Muntner P, Coresh J, Smith JC, Eckfeldt J, Klag MJ: Plasma lipids and risk of developing renal dysfunction: the atherosclerosis risk in communities study. Kidney Int 2000, 58(1):293-301.
16. Iseki K, Ikemiya Y, Kinjo K, Inoue T, Iseki C, Takishita S: Body mass index and the risk of development of end-stage renal disease in a screened cohort. Kidney Int 2004, 65(5):1870-1876.

17. Obermayr RP, Temml C, Gutjahr G, Knechtelsdorfer M, Oberbauer R, KlauserBraun R: Elevated uric acid increases the risk for kidney disease. J Am SoC Nephrol 2008, 19(12):2407-2413.

18. Madero M, Sarnak MJ, Wang X, Greene T, Beck GJ, Kusek JW, Collins AJ, Levey AS, Menon V: Uric acid and long-term outcomes in CKD. Am J Kidney Dis 2009, 53(5):796-803.

19. Iseki K, Ikemiya Y, Inoue T, Iseki C, Kinjo K, Takishita S: Significance of hyperuricemia as a risk factor for developing ESRD in a screened cohort. Am J Kidney Dis 2004, 44(4):642-650.

20. Ohno I, Hosoya T, Gomi H, Ichida K, Okabe H, Hikita M: Serum uric acid and renal prognosis in patients with IgA nephropathy. Nephron 2001, 87(4):333-339.

21. Matsuo S, Imai E, Horio M, Yasuda Y, Tomita K, Nitta K, Yamagata K, Tomino Y, Yokoyama H, Hishida A: Revised equations for estimated GFR from serum creatinine in Japan. Am J Kidney Dis 2009, 53(6):982-992.

22. Hallan S, Asberg A, Lindberg M, Johnsen $\mathrm{H}$ : Validation of the Modification of Diet in Renal Disease formula for estimating GFR with special emphasis on calibration of the serum creatinine assay. Am J Kidney Dis 2004, 44(1):84-93.

23. Cox D: Regression Models and Life-Tables. J R Stat Soc Ser B 1972, 34(2):187-220.

24. Kaplan EL, Meier P: Nonparametric Estimation from Incomplete Observations. J Am Stat Assoc 1958, 53(282):457-481

25. SPSS. SPSS for Windows VJ: Chicago: SPSS Inc 2008

26. Siu YP, Leung KT, Tong MK, Kwan TH: Use of allopurinol in slowing the progression of renal disease through its ability to lower serum uric acid level. Am J Kidney Dis 2006, 47(1):51-59.

27. Perez-Ruiz F, Calabozo M, Herrero-Beites AM, Garcia-Erauskin G, Pijoan الر: Improvement of renal function in patients with chronic gout after proper control of hyperuricemia and gouty bouts. Nephron 2000, 86(3):287-291.

28. Guideline for the management of hyperuricemia and gout (in Japanese). Japanese Society of Gout and Nucleic Acid Metabolosm 2002.

29. Ravid M, Brosh D, Ravid-Safran D, Levy Z, Rachmani R: Main risk factors for nephropathy in type 2 diabetes mellitus are plasma cholesterol levels, mean blood pressure, and hyperglycemia. Arch Intern Med 1998, 158(9):998-1004.

30. Appel GB, Radhakrishnan J, Avram MM, DeFronzo RA, Escobar-Jimenez F, Campos MM, Burgess E, Hille DA, Dickson TZ, Shahinfar S, Brenner BM: Analysis of metabolic parameters as predictors of risk in the RENAAL study. Diabetes Care 2003, 26(5):1402-1407.

31. Third Report of the National Cholesterol Education Program (NCEP) Expert Panel on Detection, Evaluation, and Treatment of High Blood Cholesterol in Adults (Adult Treatment Panel III) final report. Circulation 2002, 106(25):3143-3421.

32. Teramoto T, Sasaki J, Ueshima H, Egusa G, Kinoshita M, Shimamoto K, Daida H, Biro S, Hirobe K, Funahashi T, Yokote K, Yokode M: Diagnostic criteria for dyslipidemia. Executive summary of Japan Atherosclerosis Society (JAS) guideline for diagnosis and prevention of atherosclerotic cardiovascular diseases for Japanese. J Atheroscler Thromb 2007, 14(4):155-158.

33. Reynolds K, Gu D, Muntner P, Kusek JW, Chen J, Wu X, Duan X, Chen CS, Klag MJ, Whelton PK, He J: A population-based, prospective study of blood pressure and risk for end-stage renal disease in China. J Am Soc Nephrol 2007, 18(6):1928-1935.

34. Klag MJ, Whelton PK, Randall BL, Neaton JD, Brancati FL, Ford CE, Shulman NB, Stamler J: Blood pressure and end-stage renal disease in men. N Engl J Med 1996, 334(1):13-18.

35. Chobanian AV, Bakris GL, Black HR, Cushman WC, Green LA, Izzo JL Jr, Jones DW, Materson BJ, Oparil S, Wright JT, Roccella EJ Jr: Seventh report of the Joint National Committee on Prevention, Detection, Evaluation, and Treatment of High Blood Pressure. Hypertension 2003, 42(6):1206-1252

36. Ogihara T, Kikuchi K, Matsuoka H, Fujita T, Higaki J, Horiuchi M, Imai Y, Imaizumi T, Ito S, Iwao H, Kario K, Kawano Y, Kim-Mitsuyama S, Kimura G, Matsubara H, Matsuura H, Naruse M, Saito I, Shimada K, Shimamoto K, Suzuki H, Takishita S, Tanahashi N, Tsuchihashi T, Uchiyama M, Ueda S, Ueshima H, Umemura S, Ishimitsu T, Rakugi H: The Japanese Society of 
Hypertension Guidelines for the Management of Hypertension (JSH 2009). Hypertens Res 2009, 32(1):3-107.

37. Remuzzi G, Benigni A, Remuzzi A: Mechanisms of progression and regression of renal lesions of chronic nephropathies and diabetes. J Clin Invest 2006, 116(2):288-296.

38. Kramer H, Luke A, Bidani A, Cao G, Cooper R, McGee D: Obesity and prevalent and incident CKD: the Hypertension Detection and Follow-Up Program. Am J Kidney Dis 2005, 46(4):587-594.

39. Guideline for the Treatment of Obesity (in Japanese). Japan Society for the Study of Obesity 2006.

40. Imai E, Horio M, Nitta K, Yamagata K, Iseki K, Tsukamoto Y, Ito S, Makino H, Hishida A, Matsuo S: Modification of the Modification of Diet in Renal Disease (MDRD) Study equation for Japan. Am J Kidney Dis 2007, 50(6):927-937.

\section{Pre-publication history}

The pre-publication history for this paper can be accessed here: http://www.biomedcentral.com/1471-2369/12/31/prepub

doi:10.1186/1471-2369-12-31

Cite this article as: Kawashima et al.: Association between asymptomatic hyperuricemia and new-onset chronic kidney disease in Japanese male workers: a long-term retrospective cohort study. BMC Nephrology 2011 12:31.

\section{Submit your next manuscript to BioMed Central} and take full advantage of:

- Convenient online submission

- Thorough peer review

- No space constraints or color figure charges

- Immediate publication on acceptance

- Inclusion in PubMed, CAS, Scopus and Google Scholar

- Research which is freely available for redistribution

Submit your manuscript at www.biomedcentral.com/submit 